\title{
Determining Cochlear Implant Candidacy in Adults: Limitations, Expansions, and Opportunities for Improvement
}

\author{
Teresa A. Zwolan, Ph.D., CCC-A ${ }^{1}$ and Gregory Basura, M.D., Ph.D. ${ }^{1}$
}

\section{ABSTRACT}

The safety, efficacy, and success of cochlear implants (CIs) are well established and have led to changes in criteria used by clinicians to determine who should receive a CI. Such changes in clinical decisionmaking have out-paced the slower-occurring changes that have taken place with regulatory bodies' and insurers' indications. We review the historical development of indications for CIs, including those of the U.S. Food and Drug Administration (FDA), Medicare, Medicaid, and private insurers. We report on expansion to include patients with greater residual hearing, such as those who receive Hybrid and EAS devices, and report on recent FDA approvals that place less emphasis on the patient's best-aided condition and greater emphasis on the ear to be treated. This includes expansion of CIs to patients with single-side deafness and asymmetric hearing loss. We review changes in the test materials used to determine candidacy, including transition from sentences in quiet to sentences in noise to the recent use of monosyllabic words and cognitive screening measures. Importantly, we discuss the recent trend to recommend CIs despite a patient not meeting FDA or insurers' indications (a practice known as "off-label"), which serves as attestation that current indications need to be updated.

KEYWORDS: cochlear implant candidacy, indications, speech recognition, FDA approval

\section{ADULT COCHLEAR IMPLANT CANDIDACY}

When cochlear implants (CIs) were first approved for use in adults, the U.S. Food and
Drug Administration (FDA)-approved indications for CIs were limited to patients with bilateral profound sensorineural hearing loss (SNHL) who demonstrated no open-set speech
${ }^{1}$ Department of Otolaryngology - Head and Neck Surgery, Michigan Medicine, Ann Arbor, Michigan.

Address for correspondence: Teresa A. Zwolan, Ph.D., 4050 Brookview Ct., Ann Arbor, MI 48108

(e-mail: zwolan@umich.edu).

Barriers to Cochlear Implant Access: Acknowledging the Challenges, Changing the Future; Guest Editor, Sarah Sydlowski, Au.D., Ph.D., M.B.A.
Semin Hear 2021;42:331-341. (C) 2021. Thieme. All rights reserved. Thieme Medical Publishers, Inc., 333 Seventh Avenue, 18th Floor, New York, NY 10001, USA DOI: https://doi.org/10.1055/s-0041-1739283. ISSN 0734-0451. 
recognition. Improvements in technology have taken place since the initial introduction of CIs, leading to substantial improvements in patient outcomes. These improvements have fostered changes in clinical practice and decision-making processes related to recommendations of who should receive a CI. Many professionals argue that the rate of improvement in patient outcomes has outpaced expansion of candidacy guidelines of the FDA, Medicare, and private insurers in the United States, leading to confusion among patients and professionals regarding adult candidacy. Unfortunately, this is likely resulting in exclusion of well-qualified candidates having access to CIs.

\section{FDA APPROVAL OF COCHLEAR IMPLANTS}

The U.S. FDA has been involved with overseeing the safety and development of medical devices since 1976. ${ }^{1}$ The process that device manufacturers must follow to receive FDA approval is rigorous; it typically takes an average of 3 to 7 years to transition a new medical device from concept to market. ${ }^{2}$ CIs are considered Class III medical devices that require a premarket approval (PMA) process that includes submission of clinical data to support claims made for the device. Such claims are typically placed on the device label and are subject to approval by the FDA. Thus, approved device labeling reflects the data that were submitted as part of the PMA but may not be reflective of what clinicians recognize as best practice. Once a device has received FDA approval, making a change to the approved indications for use requires the manufacturer to submit a PMA supplement, which typically requires inclusion of substantial clinical data to support the requested change. This can be an expensive and time-consuming process for device manufacturers and often slows down expansion of FDA-approved indications.

A summary of current FDA-approved indications for CIs in adults is provided in Table 1. This information represents audiometric labeling, speech recognition labeling, and the type of speech recognition material that labeled indications are based on (i.e., sentences or words). It should be noted that some indications list a particular test and that none of the indications specify if test materials should be presented in quiet or noise. The absence of information regarding quiet or noise is beneficial, as this has made it possible for test procedures to evolve and better match clinical decisions regarding CI candidacy without requiring submission of additional PMA or investigational device exemption (IDE) paperwork to the FDA.

\section{LANDMARK CHANGES IN FDA APPROVAL}

In 2014, the FDA granted approval for people 18 years and older to receive the Cochlear Nucleus Hybrid CI (Cochlear Corporation, Sydney, Australia) device and in 2016 for adults to receive the MED-EL EAS device (MEDEL, Innsbruck, Austria; Table 1). The FDAapproved indications for these devices are considered to represent landmark changes, as patients with low-frequency thresholds in the normal range were now eligible to receive a CI and because each device bases candidacy on aided word scores for each ear rather than a sentence score obtained in the patient's best aided, usually bilateral, condition. For both devices, statements are provided regarding the maximum aided word score that can be obtained in the ear to be implanted as well as the maximum aided word score that can be obtained in the contralateral ear. Both indications represent a change in FDA-approved indications toward greater emphasis on the test results of the ear to be implanted and less emphasis upon the hearing in the better hearing ear that typically impacts the scores obtained in the best aided condition.

The Hybrid and EAS clinical trials facilitated change in clinical practice since both trials based candidacy on a monosyllabic word score and because both trials involved testing in noise as well as in quiet. Importantly, the mean postoperative scores reported in each clinical trial demonstrated that most patients performed best when tested in a bimodal condition where they used the hybrid/EAS device in one ear and a hearing aid in the other ear. ${ }^{3,4}$ This finding of bimodal benefit has been verified by others. $^{5-8}$ The Hybrid and EAS studies 
Table 1 FDA-approved Labeling for Adults for Current Cochlear Implant Systems

\begin{tabular}{|c|c|c|}
\hline$\overline{\text { Device }}$ & Audiometric indications & Speech recognition indications \\
\hline Advanced Bionics HR90K Ultra 3D & $\begin{array}{l}\text { Severe to profound, bilateral } \\
\text { sensorineural hearing loss (>70 dB } \\
H L)\end{array}$ & $\begin{array}{l}\leq 50 \% \text { for open-set sentence } \\
\text { recognition (HINT sentences) }\end{array}$ \\
\hline Cochlear Profile and Profile Plus & $\begin{array}{l}\text { Moderate to profound hearing loss } \\
\text { in the low frequencies and pro- } \\
\text { found ( } \geq 90 \mathrm{~dB} \mathrm{HL} \text { ) hearing loss in } \\
\text { the mid to high frequencies }\end{array}$ & $\begin{array}{l}\leq 50 \% \text { in the ear to be implanted } \\
\text { ( } \leq 60 \% \text { in the best-aided condition) } \\
\text { on recorded tests of open-set sen- } \\
\text { tence recognition }\end{array}$ \\
\hline Cochlear Hybrid—L24 & $\begin{array}{l}\text { Thresholds } \leq 60 \mathrm{~dB} H \mathrm{HL} \text { through } \\
500 \mathrm{~Hz} \text { and } \geq 70 \mathrm{~dB} \mathrm{HL} \text { for } 2,000 \\
\mathrm{~Hz}+\end{array}$ & $\begin{array}{l}\leq 60 \% \text { CNC word recognition in } \\
\text { the ear to be implanted, } \leq 80 \% \\
\text { CNC in contralateral ear }\end{array}$ \\
\hline $\begin{array}{l}\text { MED-EL Synchrony and } \\
\text { Synchrony } 2\end{array}$ & $\begin{array}{l}\text { Bilateral severe to profound senso- } \\
\text { rineural hearing loss (pure tone } \\
\text { average } \geq 70 \mathrm{~dB} \mathrm{HL} \text { ) }\end{array}$ & $\begin{array}{l}\leq 40 \% \text { in best-aided listening } \\
\text { condition on recorded tests of } \\
\text { open-set sentence recognition } \\
\text { (HINT sentences) }\end{array}$ \\
\hline $\begin{array}{l}\text { MED-EL Synchrony and Synchrony } \\
2 \text { EAS }\end{array}$ & $\begin{array}{l}\text { Thresholds } \leq 65 \mathrm{~dB} H \mathrm{HL} \text { through } \\
500 \mathrm{~Hz} \text { and } \geq 70 \mathrm{~dB} \mathrm{HL} \text { for } \\
2,000+\end{array}$ & $\begin{array}{l}\leq 60 \% \text { CNC word recognition in } \\
\text { the ear to be implanted and in the } \\
\text { contralateral ear }\end{array}$ \\
\hline $\begin{array}{l}\text { MED-EL Synchrony and Synchrony } \\
2 \text { for single-side deafness }\end{array}$ & $\begin{array}{l}\text { Thresholds } \geq 90 \mathrm{~dB} H \mathrm{H} \text { in the ear } \\
\text { to be implanted and normal hear- } \\
\text { ing or mild sensorineural hearing } \\
\text { loss in the other ear }\end{array}$ & $\begin{array}{l}<5 \% \mathrm{CNC} \text { word recognition in the } \\
\text { ear to be implanted }\end{array}$ \\
\hline $\begin{array}{l}\text { MED-EL Synchrony and Synchrony } \\
2 \text { for asymmetric hearing loss }\end{array}$ & $\begin{array}{l}\text { Thresholds } \geq 90 \mathrm{~dB} \mathrm{HL} \text { in the ear } \\
\text { to be implanted and mild to moder- } \\
\text { ately severe sensorineural hearing } \\
\text { loss in the other ear, with a differ- } \\
\text { ence of at least } 15 \mathrm{~dB} \text { in pure tone } \\
\text { averages between ears }\end{array}$ & $\begin{array}{l}<5 \% \text { CNC word recognition in the } \\
\text { ear to be implanted }\end{array}$ \\
\hline Oticon Neuro System & $\begin{array}{l}\text { Severe to profound hearing loss } \\
\text { (pure tone average } \geq 70 \mathrm{~dB} H \mathrm{HL} \text { at } \\
500,1,000 \text {, and } 2,000 \mathrm{~Hz} \text { ) }\end{array}$ & $\begin{array}{l}50 \% \text { or less on HINT sentences in } \\
\text { quiet or noise, in the best-aided } \\
\text { listening condition }\end{array}$ \\
\hline
\end{tabular}

Abbreviations: CNC, Consonant-Nucleus-Consonant; HINT, hearing in noise test. Source: Adapted from Gifford et al. ${ }^{9}$

demonstrated to clinicians that placement of a $\mathrm{CI}$ in a patient with better hearing in the contralateral ear resulted in overall improvements in speech recognition, even when tested in noise. Clinicians quickly learned to apply testing in noise procedures to patients who were not Hybrid or EAS candidates but who had greater aidable hearing in the contralateral ear than patients in the past.

Recently published FDA indications for the MED-EL device continue to demonstrate greater emphasis on the ear to be implanted and less emphasis on the contralateral ear. In 2019, the MED-EL device received FDA approval for use in children (ages 5 years and older) and adults with single-side deafness (SSD) and asymmetric hearing loss (AHL; Table 1). Similar to the Hybrid and EAS indications, the SSD and AHL indications base candidacy on preoperative aided word scores for the ear to be implanted with much less emphasis on the hearing in the other ear. These recent FDA-approved indications move CIs closer to the medical policies followed by other fields, namely, where FDAapproved indications do not include statements regarding the status of the contralateral body part. Examples of this unilateral focus include indications for knee and hip replacements and cataract surgery. 
Although the FDA plays a vital role in CI indications, it is important to note that the FDA governs the CI industry but does not govern the decisions of individual clinicians. ${ }^{9}$ This is evident in the FDA's wording regarding investigational use of marketed drugs, biologics, and medical devices, where they state "good medical practice and the best interests of the patient require that physicians use legally available drugs, biologics, and devices according to their best knowledge and judgment. If physicians use a product for an indication not in the approved labeling, they have the responsibility to be well informed about the product, to base its use on firm scientific rationale and on sound medical evidence, and to maintain records of the product's use and effects." ${ }^{10}$ Thus, the FDA recognizes that their approved indications may not apply to the needs of every individual and that clinicians can provide devices to patients even if they do not meet the approved indications.

Provision of a CI to a patient who does not meet the approved indications is often referred to as "off-label" use and has become common practice among CI programs in the United States. This is supported by the work of Carlson et $\mathrm{al},{ }^{11}$ who surveyed members of the American Neurotology Society (ANS) and found that $78 \%$ of respondents performed a CI for at least one off-label indication within the last 2 years of completing the survey. In our practice (an academic medical center), we have seen an increase in the number of patients interested in and receiving a CI despite not meeting traditional indications; in the past 2 years, approximately $33 \%$ of the CI surgeries performed on adults in our clinic have been done following insurance approval for off-label use of a device. Such widespread increase in off-label use of CIs signifies that current clinical best practice differs from the more restrictive labeling of the FDA.

\section{MEDICARE INDICATIONS}

The Centers for Medicare and Medicaid Services (CMS) is a federal program that determines how products will be reimbursed through Medicare. It is the largest public health insurance program and provides coverage for people
65 years of age and older, for those who are younger than 65 years with certain disabilities, and for individuals of all ages with end-stage renal disease. Unlike the FDA, which focuses on safety and effectiveness, CMS determines if coverage of a device is reasonable and necessary. Thus, FDA approval does not guarantee that a device will be covered by CMS and CMS may cover technologies for indications that the FDA has not yet approved. ${ }^{12}$

Coverage of CIs by Medicare can involve either authorization determination involving local Medicare contractors or a national coverage determination (NCD) that involves CMS issuing a single decision that local contractors and private payers frequently follow. Coverage of CIs was first approved by CMS in October 1986 and indicated "Cochlear implantation is considered a safe and efficacious therapy for adult patients with postlingual, profound, bilateral sensorineural deafness who are stimulable and who lack the unaided residual auditory ability to detect sound." ${ }^{13}$ In 1998, Medicare coverage was revised to include the 1995 Consensus Statement of the National Institutes of Health (NIH), which stated, "Indications in favor of an implant are a severe-to-profound SNHL bilaterally and open-set sentence recognition scores less than or equal to $30 \%$ under best-aided conditions." ${ }^{14}$

CMS' coverage guidelines were again modified in 2005 and have been in effect since that time. These current guidelines state, "cochlear implantation is reasonable and necessary for treatment of bilateral pre- or postlinguistic, sensorineural, moderate-to-profound hearing loss in individuals who demonstrate limited benefit from amplification. Limited benefit from amplification is defined by test scores of $\leq 40 \%$ correct in the best-aided listening condition on tape-recorded tests of open-set sentence cognition." Additionally, CMS also states, "The evidence is sufficient to conclude that a CI is reasonable and necessary for individuals with hearing test scores of $>40 \%$ and $\leq 60 \%$ only when the provider is participating in and patients are enrolled in either an FDAapproved category B IDE clinical trial, a trial under the CMS Clinical Trial Policy, or a prospective, controlled comparative trial approved by CMS as consistent with the 
evidentiary requirements for National Coverage Analyses and meeting specific quality standards." ${ }^{14}$ Additionally, CMS requires that the device be used in accordance with FDA labeling.

In July 2013, the American Cochlear Implant Alliance sponsored a study aimed at expanding Medicare coverage of CIs to include patients who obtain open-set sentence recognition scores of up to $60 \%$ in their best-aided condition. ${ }^{15}$ In October 2020, a formal request was placed with CMS to open the current NCD for reconsideration. At the time of this writing, this request has not yet been approved.

\section{MEDICARE ADVANTAGE PLANS}

It is important to note that Medicare Advantage (Part C) plans are required to at least cover the same services related to $\mathrm{CIs}$ as Medicare Part A and Part B. Unlike traditional Medicare, Part C plans often require preauthorization, and some plans may approve a request to provide a CI even when a patient does not meet traditional Medicare indications. This option to seek preauthorization outside current CMS indications is not possible with traditional Medicare Part B.

\section{COVERAGE OF CIS BY PRIVATE INSURERS}

Private insurers frequently follow CMS decisions regarding coverage of CIs. Currently, more than $90 \%$ of private employer health insurance plans and managed care organizations provide coverage benefits for the cost of CI surgery and related services. ${ }^{16}$ The indications for coverage of private insurers vary and may be the same or may differ from those approved by the FDA. Many private insurers provide opportunities for appeal if coverage is initially denied, and many will consider a request to provide a CI to a patient who does not meet their published indications, or the indications approved by the FDA. Importantly, private insurers typically perform an annual review of benefits related to CIs, enabling them to expand their indications more frequently and more easily than larger entities such as Medicare and the FDA.

\section{STATE MEDICAID}

State Medicaid plans provide coverage for persons of all ages whose income and resources are insufficient to pay for healthcare. State Medicaid plans are jointly funded by Federal and State governments but are managed by the states. Sorkin ${ }^{17}$ reported survey results for 23 U.S. clinics and noted that Medicaid was the health insurer for approximately $22 \%$ of CI surgeries for adults and that state Medicaid indications for CI vary.

\section{OTHER FORMS OF COVERAGE}

In addition to the sources cited earlier, the Veteran's Administration, the Social Security Administration (SSA), state-based vocational rehabilitation programs, and other state-based programs may cover CIs, with each entity having unique indications for coverage.

\section{CLINICAL DECISION-MAKING}

Over the years, several different test batteries have been developed to assist clinicians in evaluating patients to determine if a CI should be recommended. One of the first batteries developed was the minimal auditory capabilities (MAC) battery. ${ }^{18,19}$ This battery was designed to replace conventional speech audiometry tests for adults with severe to profound hearing loss as they often performed poorly on traditional speech recognition measures. The MAC battery was initially used widely by CI clinics to determine candidacy and included a series of tasks graded in difficulty from simple closed-set discrimination to open-set recognition of words and sentences. The initial MAC battery included the following subtests: Question/Statement, Vowels, Spondee Recognition, Noise/Voice, Accent, CID Everyday Sentences, Initial Consonants, Spondee Same/Different, SPIN High-Context Sentences, Familiar Sounds, Monosyllabic Words, Four-Choice Spondee, and Final Consonants. ${ }^{20}$

As outcomes with CIs improved, increasingly difficult test materials were incorporated into CI candidacy test batteries. In 1996, the MAC battery was replaced by the Minimum Speech Test Battery (MSTB). ${ }^{21}$ This battery was unique in that it was developed for both 
pre- and postoperative CI assessments and was developed via a collaborative effort that included representatives of the American Academy of Otolaryngology - Head and Neck Surgery, the American Academy of Audiology, and an experienced group of representatives from the CI manufacturers. ${ }^{22}$ The original MSTB included the Consonant-Nucleus-Consonant (CNC) Monosyllabic Words Test ${ }^{23}$ and the Hearing in Noise Test (HINT) sentences ${ }^{24}$ with a recommendation to present the sentences in quiet as well as in a fixed level of background noise. In 2011, the MSTB was further revised and updated to include the more difficult $\mathrm{AzBio}$ Sentences ${ }^{25}$ administered in quiet and 10-talker babble, the Bamford-Kowal-Bench Speech in Noise (BKB-SIN) test, ${ }^{26}$ and continued to include CNC Monosyllabic Words. In a recent publication, Prentiss et $\mathrm{al}^{27}$ reported that $96 \%$ of responding audiologists indicated they use the MSTB to evaluate CI candidacy of adult patients.

As reported previously, FDA indications rarely specify if a particular test needs to be used or if test materials should be presented in quiet or noise. Similarly, the Revised MSTB fails to provide a specific recommendation regarding the optimal SNR for sentence presentation when determining candidacy but instead states "the recommended SNR is +10 or $+5 \mathrm{~dB}$, depending on the speech understanding abilities of the listener." This lack of specificity has made it possible for the test procedures used by clinicians to evolve and to better match clinical decisions regarding CI candidacy. One such change came about in clinical care because of the work of Gifford et $\mathrm{al}^{28}$ who reported that HINT sentences, the test being used by most clinics to determine CI candidacy at that time, demonstrated significant ceiling effects and were found to have a poor correlation with CNC words. They reported that scores obtained on the more difficult test of AzBio sentences were less likely to demonstrate ceiling effects and were in better agreement with monosyllable word test scores and scores obtained on sentences presented in noise. This impacted revision of the MSTB and, as a result, many clinics started using, and continue to use, AzBio sentences as their primary measure to determine if adults meet indications for a CI.
As indicated earlier, clinical trials for the Nucleus Hybrid and MED-EL EAS devices included monosyllabic word testing and sentence testing in noise as part of the pre- and postoperative test protocols. These trials demonstrated to clinicians that patients with even greater preoperative hearing received benefit from CIs, and that such benefit was even greater when postoperative testing included use of the hearing in the contralateral ear. This fostered utilization of monosyllabic word scores and sentence testing in noise scores in the decision-making process for non-Hybrid and nonEAS candidates.

This protocol change is supported by the report of Prentiss et al, ${ }^{27}$ who recently noted that $100 \%$ of clinics surveyed indicated they include word tests in their pre- and postoperative test batteries, even though not all indications base candidacy on such a score. Additionally, $89 \%$ of respondents use some form of sentence testing in noise to determine CI candidacy. One recent development noted in this study is that many clinicians consider the patient's cognitive status and the patient's possession of realistic expectations when making CI candidacy decisions. These two factors are not included in the wording used in current indications but are important factors that impact outcomes and warrant consideration in the clinical decision-making process. ${ }^{29}$ Others also have recommended inclusion of measures to more comprehensively evaluate the whole patient in the preoperative CI candidacy determination process, such as questionnaires to examine health-related quality of life and communication difficulties. ${ }^{30,31}$

Importantly, the increase of provision of offlabel CIs and the use of nonstandardized measures has resulted in significant variation in CI candidacy assessment in the United States. Such variability was initially noted by Carlson et $\mathrm{al}^{11}$ and was supported by the findings of Prentiss et al. $^{27}$ This variability signals the need for incorporation of careful clinical judgment when making CI candidacy decisions and also calls for future revision of $\mathrm{CI}$ indications for adults.

\section{CALlS FOR CHANGE}

Many professionals have identified limitations in current indications and have called for 
expansion of current U.S. indications for CIs in adults. One of the earliest recommendations for expansion was made by Gifford et $\mathrm{al}^{5}{ }^{5}$ who performed a retrospective review of 22 adult CI recipients who demonstrated preoperative CNC word recognition scores of $30 \%$ or higher in the best-aided condition - an indication that exceeded the requirements for inclusion in the Nucleus Freedom clinical trial. They found that these individuals with greater preoperative speech recognition demonstrated significant improvements in postoperative speech recognition, both in the CI only and the CI plus contralateral hearing aid conditions. More recently, Perkins et $\mathrm{al}^{32}$ completed a follow-up study that included 104 recipients (105 ears) who scored greater than or equal to $30 \%$ on $\mathrm{CNC}$ words in the ear to be implanted and found similar results to their previous study: recipients demonstrated statistically significant improvement for both $\mathrm{CNC}$ words and $\mathrm{AzBio}$ sentences in quiet and noise for the $\mathrm{CI}$ alone and the bilateral listening conditions. In both instances, the authors concluded that a largescale reassessment of manufacturer and Medicare indications for adults was warranted and that such expansion would allow more hearingimpaired individuals to take advantage of the benefits offered by CIs. In the recent study, ${ }^{32}$ the authors suggest expansion of $\mathrm{CNC}$ word scores to $40 \%$ with consideration of further expansion of up to $60 \%$ in the ear to be implanted.

In 2011, Amoodi et $\mathrm{al}^{33}$ evaluated the preand postoperative speech recognition and hearing handicap of 27 adults who obtained preoperative scores outside the FDA-approved indications and demonstrated scores greater than or equal to $60 \%$ on HINT sentences. The mean scores for these subjects improved from $68.4 \%$ preoperatively to a mean score of 91.9\% 12 months postimplant. Additionally, the group demonstrated a significant improvement in hearing-related handicap. The authors concluded their results warrant the consideration of revised or expanded candidacy to allow more hearing-impaired individuals to take advantage of the benefits offered by $\mathrm{CI}$ and stated that candidacy for a CI should be considered on an individual basis rather than strictly based on a speech recognition score.
A compelling and thorough study covering expansion of audiometric requirements for a CI was recently conducted by Birman and Sanli. ${ }^{34}$ In their study, they compared outcomes for adults who had a severe loss to those with a profound loss at the time of implantation. Like the outcomes reported by Dowell, ${ }^{35}$ they found that postlingually deafened adults with preoperative severe SNHL had significantly better outcomes with a CI when compared with adults with preoperative profound SNHL. They reported quartile scores obtained at the 12month postoperative timeframe for severe and profound groups as 83 and 75\%, respectively, and reported mean scores of 32 and 26\%, respectively, for words. Based on these findings, it appears adults may perform better with a $\mathrm{CI}$ if they receive the device before their hearing loss progresses to a profound hearing loss range.

As stated previously, recent FDA approvals indicate a trend toward the use of word scores rather than sentence scores for determining CI candidacy (e.g., Nucleus Hybrid, Nucleus CI532, MED-EL EAS, and MED-EL's recent approval for SSD and AHL). Numerous investigators support the use of monosyllabic word scores as the primary metric for CI candidacy determination, as such tests are typically more difficult than sentences, meaning they are less likely to demonstrate postoperative ceiling effects than sentences. ${ }^{28,30}$ Others have indicated a preference for monosyllabic word tests, as some indications based on sentence scores may miss candidates who could benefit from a $\mathrm{CI}^{5}$ and because the semantic contextual cues available with sentences could greatly influence the accuracy of patient responses on such measures. ${ }^{30} \mathrm{~A}$ change to using word scores in adult CI candidacy consideration would also bring the United States closer to the indications used by most other countries. ${ }^{36}$

Varadarajan et $\mathrm{al}^{37}$ provided additional compelling reasons for expansion of current indications, including recent increases in the number of adults with atypical etiologies who receive benefit from $\mathrm{CIs}$, such as those with advanced otosclerosis, posttraumatic SNHL, those undergoing labyrinthectomy, and patients presenting with vestibular schwannomas. They importantly state that expansion of indications could result in improvement in the 
underutilization of CIs currently seen in the United States. $^{38}$

\section{Inclusion of Cognitive Screening}

One important recent change in candidacy determination of adults is the inclusion of cognitive screening measures. There are numerous reasons for this trend, including older adults living longer with an increased desire for social participation, ${ }^{39}$ an increase in the number of elderly patients being evaluated for CIs, ${ }^{40}$ and findings that some patients demonstrate improved cognitive function following CI. ${ }^{41} \mathrm{Sup}-$ port for inclusion of cognitive screening in candidacy evaluations was provided by Moberly et $\mathrm{al}^{29}$ and they reported that clinical measures of sentence recognition, which are currently used to determine candidacy, may be affected by neurocognitive functions and should be taken into consideration during evaluation for a CI. Additional support for such inclusion is provided by Shen et $\mathrm{al}^{39}$ who noted that mild cognitive impairment (MCI) is associated with many disorders that have high incidence in the older population, including hearing loss, and that symptoms of hearing loss often mimic the signs of cognitive decline, making differentiation and presence/absence of the two diagnoses important. Preoperative identification of MCI is important for both otologists and audiologists since hearing loss is a modifiable age-associated condition whose treatment may decrease the risk of MCI and dementia. ${ }^{42}$ Shen et al, ${ }^{39}$ Beck et $\mathrm{al}^{43}$ and Souza ${ }^{44}$ all indicated that audiologists are well positioned for identifying cognitive decline in patients, as their evaluations are typically focused on evaluating patients' communication abilities, which is strongly influenced by cognition.

However, it does not appear that cognitive screening has been widely integrated into clinical CI care. In a survey of 99 CI audiologists, Prentiss et $\mathrm{al}^{27}$ found that $74 \%$ of respondents indicated they seldom or never include a cognitive screening assessment in their candidacy evaluations. However, of the 40 respondents who reported administering cognitive screening measures, $45 \%$ reported they modified their test protocol based on the screening results. Although fewer than half of the audiologists surveyed indicated they administered cognitive screening tests, $57 \%$ ranked cognition as a moderately important to highly important factor in clinical decision-making regarding candidacy. Additionally, 41\% of respondents (25/61 responses) indicated they felt cognitive impairment was a contraindication to CI candidacy. In summary, it appears that cognitive screening should have a place in CI candidacy evaluations of adults, as identification of MCI and timely treatment of the hearing loss could lead to improved quality of life for many of our elderly CI patients.

Timely identification and treatment of significant hearing loss is important for all adults and not just the elderly. Dowell ${ }^{35}$ analyzed the outcomes of 310 adult CI candidates and concluded that estimates of postoperative speech perception scores following CI are significantly better if implantation occurs relatively soon after the onset of severe hearing loss and prior to the loss of all auditory function. This is supported by the work of others who have reported that duration of hearing loss is inversely related to CI performance. ${ }^{45-47}$ Thus, early referral and provision of a CI soon after meeting candidacy could positively impact the results patients receive with CIs.

\section{SUMMARY}

$\mathrm{CI}$ indications have evolved over time as technology and outcomes have improved. As can be seen from the descriptions provided, there is a plethora of indications that clinicians and patients must maneuver before a $\mathrm{CI}$ can be recommended or provided. This provides challenges for clinicians, for insurers, and, most importantly, for potential CI recipients.

The finding that off-label usage of CI devices has become commonplace in many clinics could be viewed as attestation that current indications need major updating. ${ }^{11}$ The amount of time it takes to obtain approval for off-label use of a device may involve months or years of administrative effort, and still the procedure may ultimately be denied. This means many CI candidates will not receive treatment if their clinic is not willing or able to perform the extra steps needed to obtain offlabel approval for them to receive a CI. 
Importantly, the inability to provide muchneeded hearing technology in a timely fashion could result in reduced outcomes with a $\mathrm{CI}$ and could negatively impact communication and cognition.

Current indications for CIs should be updated to include the changes that have taken place in clinical care, such as the inclusion of updated test materials in candidacy test batteries, such as word scores for the ear to be implanted, elimination of consideration of the patients' best-aided condition, and inclusion of cognitive screening measures for elderly patients. When considering wording for future indications, perhaps we should look to the FDA's wording regarding off-label devices, which supports decisions incorporating good medical practice, the best interest of the patient, and decision-making based on the best knowledge and judgment of the clinician who is making the decision and providing the treatment. Such changes will make it possible for greater numbers of individuals who are candidates for a $\mathrm{CI}$ to benefit from this life-changing technology. Importantly, there is a need for referral sources to become increasingly aware of recent changes in candidacy, to recognize that clinics are able to provide CIs even if a patient does not meet FDA indications, and to understand that early referral and treatment will maximize patient outcomes. Only when such changes occur will we be able to provide adequate access to the important life changes that CI technology can provide.

\section{CONFLICT OF INTEREST}

Cochlear Americas: Advisory board member and consultant (unpaid). Envoy Medical: Advisory board member (unpaid). Institute for Cochlear Implant Training Course Director and Instructor.

\section{REFERENCES}

1. Van Norman GA. Drugs, devices, and the FDA: Part 2: An overview of approval processes: FDA approval of medical devices. JACC Basic Transl Sci 2016;1(04):277-287

2. Fargen KM, Frei D, Fiorella Det al.. The FDA approval process for medical devices: an inherently flawed system or a valuable pathway for innovation? J Neurointerv Surg 2013;5(04):269-275

3. Roland JT Jr, Gantz BJ, Waltzman SB, Parkinson AJMulticenter Clinical Trial Group. United States multicenter clinical trial of the cochlear nucleus hybrid implant system. Laryngoscope 2016;126 (01):175-181

4. Pillsbury HC III, Dillon MT, Buchman CAet al.. Multicenter US clinical trial with an electricacoustic stimulation (EAS) system in adults: final outcomes. Otol Neurotol 2018;39(03):299-305

5. Gifford RH, Dorman MF, Shallop JK, Sydlowski SA. Evidence for the expansion of adult cochlear implant candidacy. Ear Hear 2010;31(02):186-194

6. Hinder D, Linder TE, Schlegel-Wagner C, Candreia $\mathrm{C}$. Benefit of bimodal stimulation with cochlear implant and hearing aid in elderly patients. [in German]Laryngorhinootologie 2017;96(07): 456-460

7. Devocht EMJ, Janssen AML, Chalupper J, Stokroos RJ, Kingma H, George ELJ. Self-assessment of unilateral and bimodal cochlear implant experiences in daily life. PLoS One 2020;15(12): e0242871

8. Mancini P, Dincer D'Alessandro H, Portanova Get al.. Bimodal cochlear implantation in elderly patients. Int J Audiol 2021;60(06):469-478

9. Gifford R, Navarro C, Macy P, Blair L. FDA candidacy for cochlear implantation. In: Gifford Red.. Cochlear Implant Patient Assessment, Evaluation of Candidacy, Performance and Outcomes. 2nd ed.San Diego: Plural Publishing; 2020:1-11

10. U.S. Food and Drug Administration Information Sheet: "Off-Label" and Investigational Use of Marketed Drugs, Biologics, and Medical Devices. Guidance for Institutional Review Boards and Clinical Investigators. Content current as of May 5, 2020 Accessed July 21, 2021 at: https:// www.fda.gov/regulatory-information/search-fdaguidance-documents/label-and-investigationaluse-marketed-drugs-biologics-and-medicaldevices

11. Carlson ML, Sladen DP, Gurgel RK, Tombers NM, Lohse CM, Driscoll CL. Survey of the American Neurotology Society on Cochlear Implantation: Part 1, Candidacy assessment and expanding indications. Otol Neurotol 2018;39 (01):e12-e19

12. Chambers JD, May KE, Neumann PJ. Medicare covers the majority of FDA-approved devices and Part B drugs, but restrictions and discrepancies remain. Health Aff (Millwood) 2013;32(06): 1109-1115

13. CMS.gov. Decision Memo for Cochlear Implantation (CAG-00107N). Accessed July 21, 2021 at: https://www.cms.gov/medicare-coverage-database/details/nca-decision-memo.aspx? NCAId=134\#: :text=Cochlear $\% 20$ implants $\%$ 
20were $\% 20$ first $\% 20$ covered, $\% 2$ C $\% 20$ dated $\%$ 20June\%2030\%2C\%201986

14. U.S. Department of Health \& Human Services, National Institutes of Health, NIH Consensus Development Program Archive. Cochlear Implants in Adults and Children. Consensus Development Conference Statement May 15-17, 1995. Accessed July 21, 2021 at: https://consensus.nih.gov/1995/ 1995 cochlearimplants100html.htm

15. Zwolan TA, Kallogjeri D, Firszt JB, Buchman CA. Assessment of cochlear implants for adult Medicare beneficiaries aged 65 years or older who meet expanded indications of open-set sentence recognition: a multicenter nonrandomized clinical trial. JAMA Otolaryngol Head Neck Surg 2020;146 (10):933-941

16. Sorkin D, Thomas MA. Cochlear Implantation: Health insurance and other possible ways of gaining Coverage. American Cochlear Implant Alliance (ACIA) Accessed July 21, 2021 at: https:// www.acialliance.org/page/HealthIns

17. Sorkin DL. Impact of Medicaid on cochlear implant access. Otol Neurotol 2019;40(03): e336-e341

18. Fifer RC, Stach BA, Jerger JF. Evaluation of the minimal auditory capabilities (MAC) test in prelingual and postlingual hearing-impaired adults. Ear Hear 1984;5(02):87-90

19. Owens E, Kessler DK, Raggio MW, Schubert ED. Analysis and revision of the minimal auditory capabilities (MAC) battery. Ear Hear 1985;6(06): 280-290

20. Auditec, Inc.. Minimal Auditory Capabilities (MAC) September 22, 2015. Accessed July 21, 2021 at: https://auditec.com/2015/09/22/minimal-auditory-capabilities-mac

21. Luxford WMAd Hoc Subcommittee of the Committee on Hearing and Equilibrium of the American Academy of Otolaryngology-Head and Neck Surgery. Minimum speech test battery for postlingually deafened adult cochlear implant patients. Otolaryngol Head Neck Surg 2001;124(02): 125-126

22. Gifford R. Adult cochlear implant candidate selection. In: Gifford Red.. Cochlear Implant Patient Assessment, Evaluation of Candidacy, Performance and Outcomes. 2nd ed.San Diego: Plural Publishing; 2020:13-36

23. Peterson GE, Lehiste I. Revised CNC lists for auditory tests. J Speech Hear Disord 1962; 27:62-70

24. Nilsson M, Soli SD, Sullivan JA. Development of the Hearing in Noise Test for the measurement of speech reception thresholds in quiet and in noise. J Acoust Soc Am 1994;95(02):1085-1099

25. Spahr AJ, Dorman MF, Litvak LMet al.. Development and validation of the AzBio sentence lists. Ear Hear 2012;33(01):112-117
26. Etymotic, Inc.. BKB-SIN TM Speech-in-Noise Test. Accessed July 21, 2021 at: www.auditorypotential.com/MSTBfiles/MSTBManual2011-0620\%20.pdf

27. Prentiss S, Snapp H, Zwolan T. Audiology practices in the preoperative evaluation and management of adult cochlear implant candidates. JAMA Otolaryngol Head Neck Surg 2020;146(02):136-142

28. Gifford RH, Shallop JK, Peterson AM. Speech recognition materials and ceiling effects: considerations for cochlear implant programs. Audiol Neurotol 2008;13(03):193-205

29. Moberly AC, Castellanos I, Mattingly JK. Neurocognitive factors contributing to cochlear implant candidacy. Otol Neurotol 2018;39(10):e1010-e1018

30. Sladen DP, Gifford RH, Haynes Det al.. Evaluation of a revised indication for determining adult cochlear implant candidacy. Laryngoscope 2017; 127(10):2368-2374

31. Wick CC, Kallogjeri D, McJunkin JLet al;CI532 Study Group. Hearing and quality-of-life outcomes after cochlear implantation in adult hearing aid users 65 years or older: a secondary analysis of a nonrandomized clinical trial. JAMA Otolaryngol Head Neck Surg 2020;146(10):925-932

32. Perkins E, Dietrich MS, Manzoor Net al.. Further evidence for the expansion of adult cochlear implant candidacy criteria. Otol Neurotol 2021;42 (06):815-823

33. Amoodi HA, Mick PT, Shipp DVet al.. Results with cochlear implantation in adults with speech recognition scores exceeding current criteria. Otol Neurotol 2012;33(01):6-12

34. Birman CS, Sanli H. Cochlear implant outcomes in patients with severe compared with profound hearing loss. Otol Neurotol 2020;41(04):e458-e463

35. Dowell RC. The case for earlier cochlear implantation in postlingually deaf adults. Int J Audiol 2016;55(Suppl 2):S51-S56

36. Vickers D, Kitterick P, Verschuur Cet al.. Issues in cochlear implant candidacy. Cochlear Implants Int 2016;17(Suppl 1):1-2

37. Varadarajan VV, Sydlowski SA, Li MM, Anne S, Adunka OF. Evolving criteria for adult and pediatric cochlear implantation. Ear Nose Throat J 2021;100(01):31-37

38. Sorkin DL, Buchman CA. Cochlear implant access in six developed countries. Otol Neurotol 2016;37 (02):e161-e164

39. Shen J, Anderson MC, Arehart KH, Souza PE. Using cognitive screening tests in audiology. Am J Audiol 2016;25(04):319-331

40. Fakurnejad S, Vail D, Song Y, Alyono J, Blevins NH. Trends in age of cochlear implant recipients, and the impact on perioperative complication rates. Otol Neurotol 2020;41(04):438-443

41. Cosetti MK, Pinkston JB, Flores JMet al.. Neurocognitive testing and cochlear implantation: 
insights into performance in older adults. Clin Interv Aging 2016;11:603-613

42. Uchida Y, Sugiura S, Nishita Y, Saji N, Sone M, Ueda H. Age-related hearing loss and cognitive decline - the potential mechanisms linking the two. Auris Nasus Larynx 2019;46 (01):1-9

43. Beck D, Weinstein BE, Harvey M. Issues in cognitive screenings by audiologists. Hearing Review; January 21, 2016

44. Souza P. The Importance of Cognitive Assessment in Audiology Practice. AudiologyOnline, February 11, 2019. Accessed July 21, 2021 at: https:// www.audiologyonline.com/articles/20q-importance-cognitive-assessment-in-24433

45. Holden LK, Finley CC, Firszt JBet al.. Factors affecting open-set word recognition in adults with cochlear implants. Ear Hear 2013;34(03):342-360

46. Leung J, Wang NY, Yeagle JDet al.. Predictive models for cochlear implantation in elderly candidates. Arch Otolaryngol Head Neck Surg 2005;131 (12):1049-1054

47. Rubinstein JT, Parkinson WS, Tyler RS, Gantz BJ. Residual speech recognition and cochlear implant performance: effects of implantation criteria. Am J Otol 1999;20(04):445-452 